\title{
Sustainable Development Planning: A Case of Public Participation using Online Forums
}

\author{
Nigel J. Martin, ${ }^{1 *}$ John L. Rice ${ }^{2}$ and Sumit K. Lodhia ${ }^{3}$ \\ ${ }^{1} T$ The Australian National University - Accounting Q Bus Info Sys, Canberra, Australia \\ ${ }^{2}$ Griffith University - Griffith Business School, Gold Coast, Qld, Australia \\ ${ }^{3}$ University of South Australia - Accounting, Adelaide, SA, Australia
}

\begin{abstract}
Public participation in Sustainable Development Planning (SDP) of cities represents significant challenges to governments and private organizations responsible for developing infrastructure. In this study, a regional government used a series of electronic discussion papers and questions to enable online forum discussions and exchanges between 196 participants on the major SDP issues related to city development up to 2030. This study used a rigorous and structured QSR NVIVO analysis of 690 online forum postings to determine the participants' major SDP concerns for the city over a 20-year period. The collective results of the investigation show that future integrated transport networks, higher density residential and commercial land use, and sustainable population growth are still the subject of concern and intense debate among forum participants, SDP experts and the government. The research also demonstrates the capacity of green information and technology systems to serve as important mechanisms for SDP participation and consultation. Copyright (C) 2012 John Wiley \& Sons, Ltd and ERP Environment
\end{abstract}

Received 1 November 2011; revised 30 March 2012; accepted 17 April 2012

Keywords: online forums; public participation; sustainable development; stakeholder engagement

\section{Introduction}

T HE PARTICIPATORY APPROACH TO SUSTAINABLE DEVELOPMENT PLANNING (SDP) HAS LONG BEEN CHAMPIONED AS A cornerstone of modern democracies and societies. The benefits of these broad-ranging engagements with the community include the capacity to combine and integrate stakeholders, build on local knowledge and expertise, gain planning and implementation commitment, assure equitable involvement of community members and, above all, empower citizens to take action and live sustainably. In essence, the application of participatory planning processes is a key enabler of future sustainable development (Thrupp et al., I994).

For cities and concentrated regions, especially those that possess aging and widespread infrastructure, the future development pathway may be complex and uncertain (Bagheri and Hjorth, 2007). Although some of these complexities are problematic for longer-term decision making and governance, theory suggests that, even in the face of evolving global environment and climate science, forward planning and comprehensive analysis are essential (Brueck, 2005;

*Correspondence to: Dr Nigel J. Martin, The Australian National University - Accounting \& Bus Info Sys, CBE Bldg 26c Rm3.20 Acton Campus, Canberra 0200, Australia. E-mail: nigel.martin@anu.edu.au 
Karlsson, 2005). We argue that, under these circumstances, positive engagements with the public on SDP issues are a priority for future developments.

In this paper, we address the important issue of public participation related to SDP using Canberra, Australia's national capital, as a case in point. In doing this, we examine the growing need to engage with communities and regions on issues of sustainable development in line with the high-level agreements reached at the United Nations Climate Change Conference in Cancun, Mexico in late 2010 (United Nations, 20I0). In a practical sense, we follow Haughton and Hunter (2003), who asserted the importance of sustainable cities, particularly in relation to urban infrastructure planning, settlements and population growth, pollution control, water resources management, and the capacity to understand the regional and global dynamics of development. Accordingly, we have two aims for the research. First, we are interested in assessing what stakeholders consider to be important in relation to the city's future sustainable development. Second, we are interested in examining the stakeholder engagement process where the interactive online forums provide a channel for public participation. The combination of these aims should allow us to understand and comprehend the key SDP issues confronting the community; while observing and reflecting on the public participation and engagement process in the electronic domain.

Other studies in this area suggest that equitable, democratic and multi-group participation, shared decision making, and integrative thinking and implementation form an important part of the larger SDP process (Healey and Shaw, I997; Roseland, 2000; Shutkin, 2000; Conroy and Berke, 2004). Our intention is to extend these considerations and analyses to include the stakeholder outputs of the process, coupled with a discussion of the online participation dynamic. We suggest that this will make a valuable contribution to our understanding of SDP, particularly in the light of evolving public participation techniques (e.g. use of Internet systems, social network conversations). The balance of this paper will discuss some of the literature surrounding SDP and the associated processes, the research context and method, the results of the analysis, and provide our concluding statements.

\section{Sustainable Development - Planning and Process}

In this study, we place strong emphasis on the planning function and processes related to sustainable development. The planning literature specific to sustainable development provides a broad discourse. Literature that focuses on the sustainable development of cities and regions delivers important foundation principles for SDP (Moffatt, I996; Girardet, I999; Holland, I999; Haughton and Hunter, 2003; The World Bank, 2010). Principles for sustainable development would include intelligent materials and green technology design; accounting for environmental costs; widespread public participation; collective preventative action rather than afterthought; minimization of waste; and, enhanced sustainability through research. Alternative studies look at narrower investigations of city-based sustainability, including urban and waste water management systems (Hellström et al., 2000) and evaluations of land-use structures and management (Thinh et al., 2002). Hence, the literature suggests that sustainable development studies and inquiries can take various forms.

In relation to this study, some research programmes in the area of city-level sustainable development offer arguments that the planning and developmental pathways are often difficult and challenging (Beatley, I995; Caldwell, I984; McDonald, I996; Satterthwaite, I997; Blassingame, I998; Agyeman and Evans, 2003; Winston, 2010). These studies point to issues such as the negative impacts from unsustainable developments, lack of integrated governmental planning, limited progress towards regional sustainability, insufficient political resolve and vision, and poorly directed policies, as barriers. In contrast, the balancing arguments for SDP highlight the importance of acknowledging the population and ecological limits of regions, including societal equity in our thinking, ensuring that we offer living choices and options, meeting societal objectives; and continually accounting for the social and environmental costs of our decisions (Beatley, I995; McDonald, I996). In our study, we support the latter perspective and assert that any difficulties and challenges only serve to make constructive SDP more important.

In relation to the SDP process, several studies feature prominently in this area (McDonald, I996; Macnaghten and Jacobs, I997; Roseland, 2000; Davidson, I996; Hjorth and Bagheri, 2006; Bagheri and Hjorth, 2007). As an example, the participative planning process has been described as a sequence of activities where a problem, planning goals and objectives, and resources are identified; followed by discussions, information gathering and action plans that are 


\section{Sustainable Development Planning and Public Participation}

implemented and evaluated (Davidson, I996). Overall, these studies demonstrate that a participative planning process can have substantial impacts on the future development of regions through the creation of inspired actions, strong commitment, and measured controls (McDonald, I996; Macnaghten and Jacobs, I997; Roseland, 2000, 2005; Davidson, I996). In particular, some inquiries highlight the importance of adequate citizen agency and participative engagement with communities as part of the trust building and action-taking agenda (Macnaghten and Jacobs, I997; Davidson, I996). In further examples, community-based planning in the United States, Canada and Brazil demonstrates the values and commitment to future sustainability that can be created through positive citizen participation (Roseland, 2000).

An integrated approach to SDP is also a focal point in the literature (Barbier, I987; McDonald, I996; Roseland, I997, 2000, 2005; Giddings et al., 2002; Agyeman and Evans, 2003). In essence, these studies assert that economic, environmental and social issues raised by stakeholders must all be considered in the SDP process. Integrated SDP places community and governments at the centre of the sustainable development process, thereby reinforcing the importance of public participation mechanisms (Roseland, 2000; John, 2009). Several studies in the area of sustainable development argue that public participation is a vital element in the process (Thrupp et al., I994; McDonald, I996; Macnaghten and Jacobs, I997; Scott, I997; Roseland, 2000; Shutkin, 2000; Agyeman and Evans, 2003; Conroy and Berke, 2004; Luke, 2005). Indeed, some studies argue that the success of SDP initiatives is dependent on strong levels of participation (Baber and Bartlett, 2005; Koontz, 2006), whereas other literature considers the participation to represent positive community partnerships that build trust and mutual support (Wang, 200I; Berner et al., 20II).

Overall, public participation in SDP assists in promoting consensus and collective decisions (Wang, 200I; Reed, 2008), democratic social structures (Webler et al., 200I; Webler and Tuler, 2006), and long-term commitment to the sustainability of our communities (Portney and Berry, 20I0). This position is summarized in Shutkin (2000) who argues that:

members of a particular geographic and political community should engage in planning and organizing activities to ensure a future that is environmentally healthy and economically and socially vibrant at the local and regional levels. It is based on the notion that environmental quality and economic and social health are mutually constitutive.

Our research framework supports the 'public participation' assertion of Shutkin (2000), and is based on the sustainable development model created by Macnaghten and Jacobs (I997) (see Figure I).

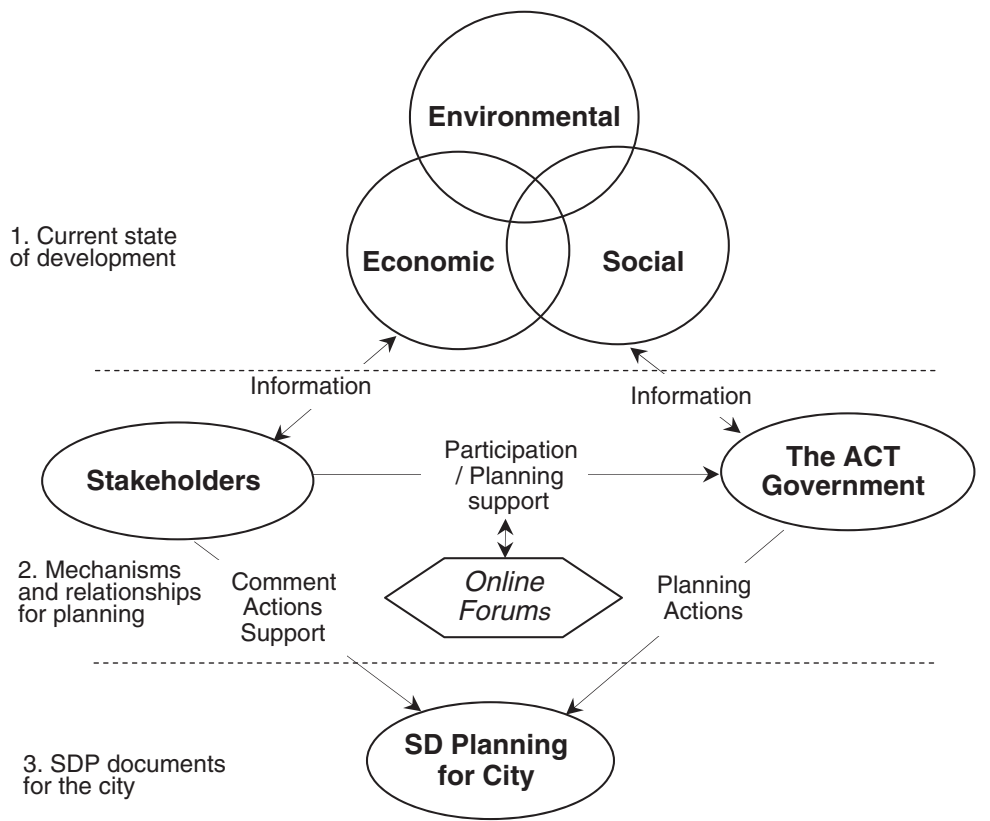

Figure 1. Research framework (adapted from Macnaghten and Jacobs, 1997) 
The model is cast in three layers and depicts: (I) the current state of development in the city, (2) the mechanisms and relationships for planning actions and (3) the SDP documents created from the process. In our case, information on the current state of development is exchanged between stakeholders and the Australian Capital Territory (ACT) government (layer I). The stakeholders participate in the SDP process through communication channels (e.g. radio, public forums, random telephone surveys), with our research concentrated on public participation, including statements, actions and support, conducted using the online forums (layer 2).

Importantly, the use of online and electronic exchange data sources for public participation is grounded in several other studies that uncovered knowledge sharing, collective intelligence, stronger senses of community, and democratic involvement benefits attributable to this communication medium (Craig, I998; Katz and Rice, 2002; Conroy and Evans-Cowley, 2006; Howard and Gaborit, 2007; Brabham, 2009). The key planning documents that emerged from the participation process were the public consultation outcomes report (layer 3) (Elton Consulting, 20I0) and the Draft ACT Planning Strategy (ACT Government, 20II).

\section{Research Case Context}

In 2004, the ACT government created the 'Canberra Plan' as a strategic framework to guide city development over the coming generation (ACT Government, 2004a). That framework included economic, social and spatial planning principles for sustainable development, particularly the Canberra (including the Civic Central Business District) and Central areas and its five major town centres (Belconnen, Woden, Tuggeranong, Weston Creek and Gungahlin). As an example, spatial planning targets and compact development aspirations, related to residential and employment intensification and urban growth containment, were applied under the Canberra Spatial Plan (Figure 2) (ACT Government, 2004b). It should be noted that the planning framework must comply with the federal government's National Capital Plan (related to developments that have national capital significance) and the Territory Plan (a statutory plan governing land use and development in the ACT).

During August to November 20I0, under the Sustainable Future Programme (part of the latest version of the Canberra Plan), the ACT government engaged in a broad-ranging community consultation and discussion on the kind of capital city citizens wanted to live in by the year 2030 (ACT Government, 2008, 2010a). The aim of the participative discussion was to involve as many members of the public, using various consultation methods and techniques, including public workshops, focus groups, scale spatial models placed in shopping centres, random telephone surveys, and online discussions forums. The government issued short discussion papers in the areas of environmental (e.g. water usage, energy consumption reduction), social (e.g. living choices, cultural significance), and economic (e.g. funding, resource allocation) sustainability, to stimulate interactive discussions, and generate planning ideas for the future of the city (ACT Government, 20IOa).

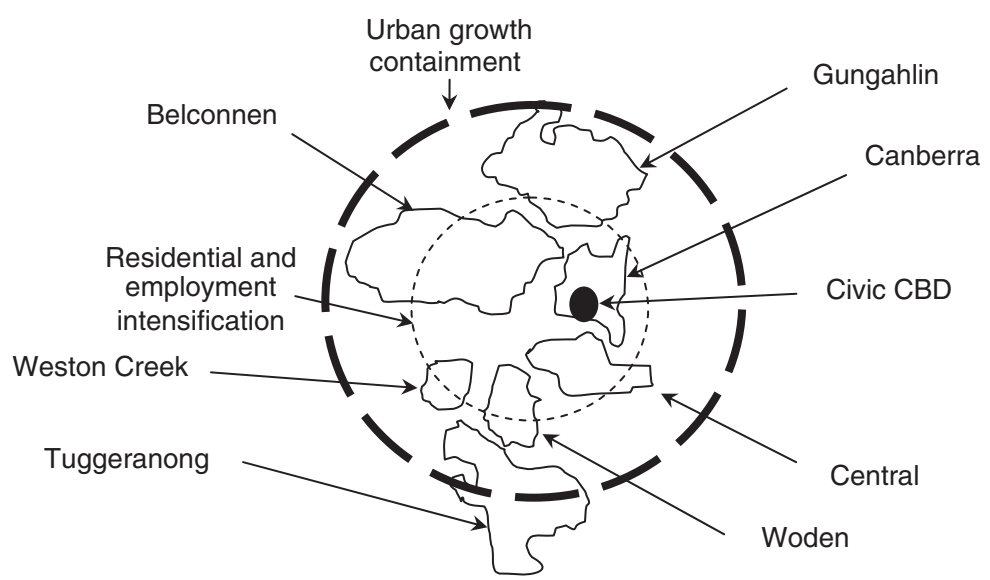

Figure 2. Example of city spatial planning (ACT Government, 2004b) 


\section{Sustainable Development Planning and Public Participation}

The statements, ideas and discussion points were gathered and compiled into an independent (outcomes) report for use in future SDP documents (Elton Consulting, 20IO), including the ongoing updates to the Canberra city spatial plan (ACT Government, 2004b), The Sustainable Transport Plan for the ACT (ACT Government, 2004c), ACT Climate Change Strategy 2007-2025 (ACT Government, 2007) and the Draft ACT Planning Strategy (ACT Government, 20II).

\section{Research Method}

The study's research method used a proven qualitative technique to collect, structure and code participants' online discussion forum statements (Miles and Huberman, I997; Denzin and Lincoln, 2005). In this respect, the study has been conducted in the tradition of other stakeholder inquiries where the participants offered views on the primary issue of concern (Freeman, I984; Donaldson and Preston, I995; Freeman et al., 2004). The data collected from the online discussion forums covered 690 statements from ig 6 online-registered participants on the city's SDP (380 social, 254 environmental and 56 economic) (ACT Government, 20IOa). Eighty-eight per cent of the participants elected to have their identities suppressed, with all participants' personal information subjected to strict privacy rules under the forum. Also, the data structure created for this study mirrors the three sustainability dimensions and the constituent issues (Corley and Gioia, 2004).

To manage and code the data, we created a project (Canberra_2030) using the QSR NVIVO Version 8 analytical software (Walsh, 2003). Participant statements were collected directly from the online forums and copied verbatim into document files for further processing (i.e. internal documents for the NVIVO project). A tree node structure was developed with national capital sustainability assigned as the apex node, the three dimensions of sustainability as major branch nodes, and the sustainability dimension issues as sub-branch nodes (Figure 3). The sub-branch nodes correspond directly to the sustainability discussion papers issued by the government (ACT Government, 20Ioa).

Each participant statement was coded within the sub-branch node to maintain and assure issue or construct integrity. The coded statements were then axially collapsed and transformed into a summary of SDP issues for each

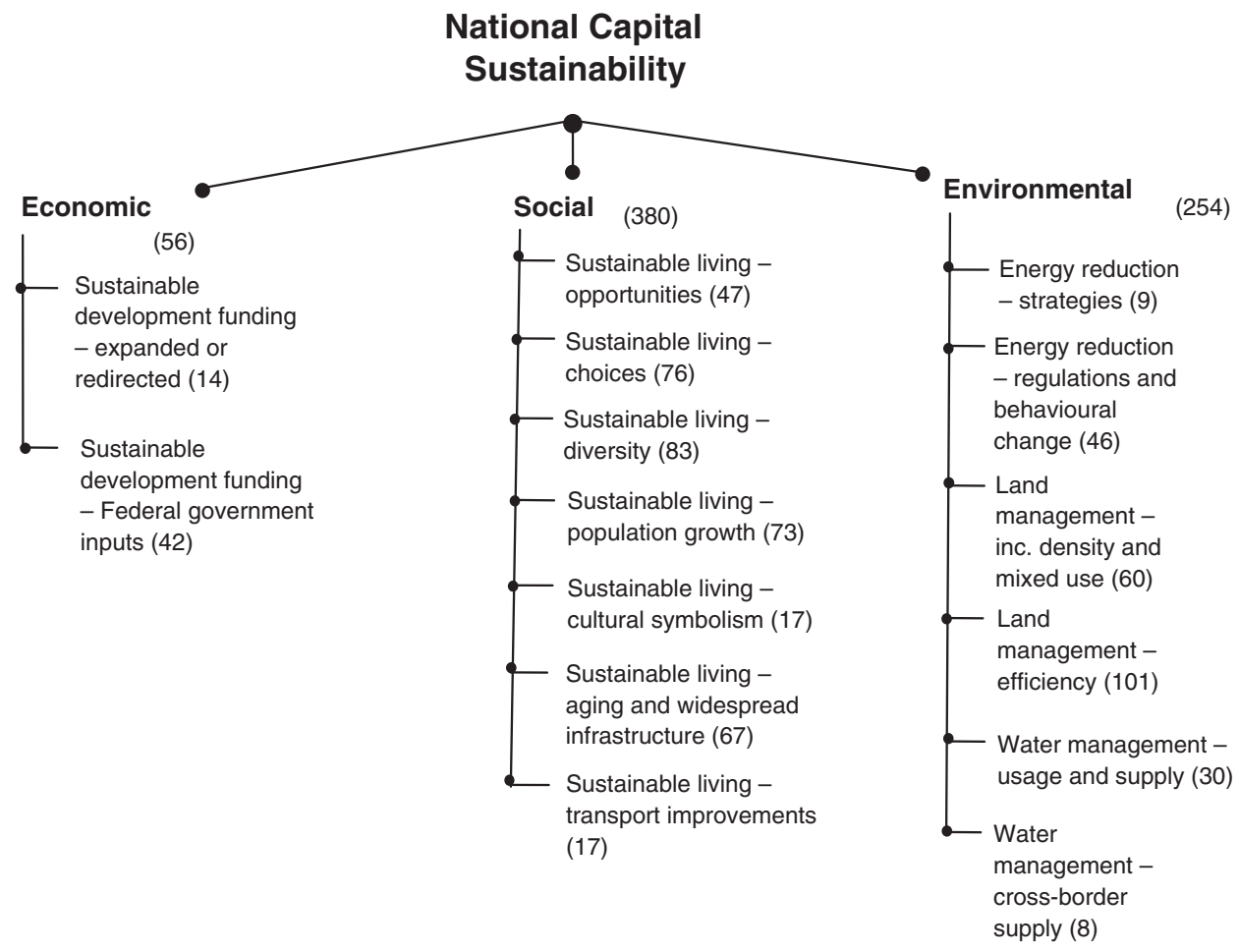

Figure 3. National Capital Sustainability - Nvivo Node Structures (numbers of statements in brackets) 
sustainability dimension (Miles and Huberman, I997; Denzin and Lincoln, 2005). As a final step, cross-dimensional linkages were identified and a summary of the highest-ranked SDP issues was created.

\section{Discussion of Results}

The results are presented as a summary of the highest-ranked SDP issues within each sustainability dimension as shown in Table I. A summary of the key results related to the online participation process is also included in the discussion.

\section{SDP Issues - Social Dimension}

The social dimension of sustainability attracted the highest number of participatory statements. From these exchanges, three important issues emerged for future development. First, a number of participants argued that an integrated transport network that combined the current airport, interstate train, bus, motor vehicle, bicycle, taxi and hire car providers, with a new and efficient city-wide light rail system, was an essential plank for future sustainability. Participants argued strongly against the current motor vehicle dependency (with the associated high per capita carbon emissions) observable in the city (i.e. single occupant cars in clogged peak hour traffic). Government benchmark studies and expert forums support this position, showing that city residents can have a carbon footprint up to 32 times higher than exemplar sustainable developments in Europe and North America (ACT Government, 20Iob), while agreeing that the city needs improved integrated transport systems (PCA, 20II).

Second, population expansion beyond the current 359,000 residents was opposed (56 statements). Participants asserted the need to stabilize population growth in the city because of pressures on the environment and biodiversity, a lack of suitable infrastructure, and the potential for future overcrowding. A typical online comment opposing population growth is offered as follows:

Becoming a liveable sustainable city does not mean growing to 500,000 people as proposed. I agree with Jet, we need to be smarter. Many European cities have stable populations yet achieve a high level of economic productivity, social and

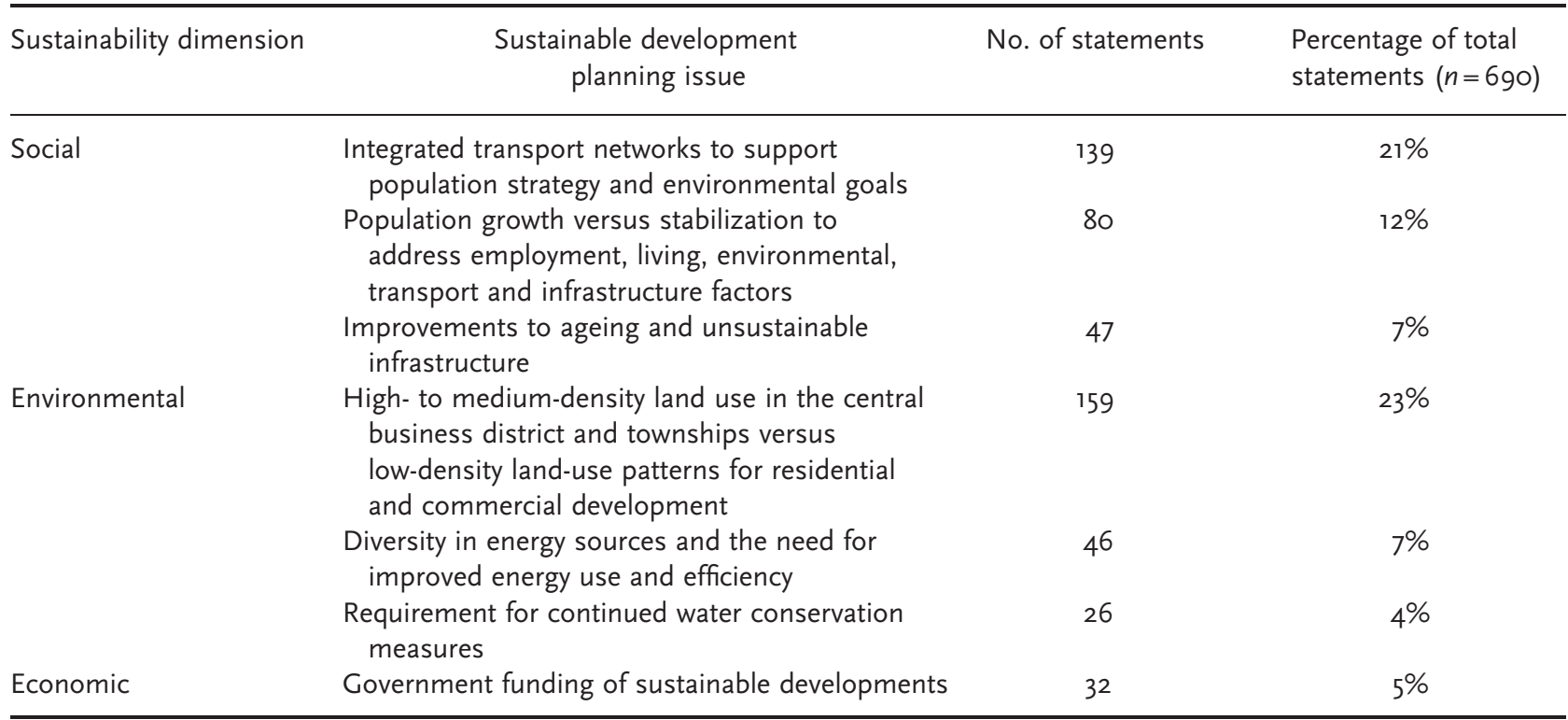

Table 1. Highest ranked sustainable development planning issues identified through public participation 


\section{Sustainable Development Planning and Public Participation}

cultural activity, and are vibrant and socially inclusive. I suspect most Canberrans do not support continued population growth into increasingly remote urban sprawl. ('Aroona' - online posting 09.33 h, 30 August 20I0)

Alternatively, participants who supported population growth (24 statements) argued that it is an essential part of future sustainability considerations, particularly when employment and new jobs, social vibrancy, long-term residency, quality living arrangements, and improved transport networks are integrated into the planning process. While these opposing views show that the issue of city-based population growth is a highly contentious and emotive issue, the population debate has moved to the national level. Importantly, the Australian government has issued a sustainable population strategy to guide the development of sustainable cities and communities, specifically in relation to employment, education, living conditions, amenity and the natural environment factors (Commonwealth of Australia, 20II). Accordingly, any future population changes in the city will need to generally comply with this national framework and the objectives for sustainable living and development.

Third, around $7 \%$ of participant statements argued for future infrastructure improvements, including planned retail developments, community gardens and open-air recreation areas, and improved waste management processing systems. In addition, we also noted with disappointment that the need for improved and equitable accommodation and facilities for socially diverse, disadvantaged and aged residents of the city failed to attract a larger number of participant exchanges (six statements). Arguably, the redevelopment of socially equitable city infrastructure is worthy of further discourse and debate in the community (Boshoff, I996; Towell, 20II).

\section{SDP Issues - Environmental Dimension}

The issue of land use and management generated the largest number of statements within the environmental dimension. Approximately $23 \%$ of all online exchanges debated the relative merits of higher-density and lower-density residential and commercial properties. The majority of statements ( $15 \%)$ supported increased mixed-use property densities, centralized in the Canberra and Central areas and town centres, on the basis of arresting future urban sprawl, enabling rapid transit transport networks, maintaining environmental green belts between townships and central areas, and increasing land-use efficiencies. A typical online statement is offered as follows:

Civic CBD [central business district] is the obvious one. I would like to see more mixed-use high-density (i.e. shops on lower levels, commercial next few floors above, and residential till the top). Currently due to groups of commercial-only areas in Civic, they become dead zones afterhours and on the weekends. If there were more mixed-use high-density building then areas would be always vibrant, in use, and allow for people (that choose to) live near work. Other areas that could do with a similar treatment are the major centres like Tuggeranong, Woden and Belconnen. ('NRD8OY' - online posting I8.28 h, I3 October 20I0)

On balance, dissenting views questioned the motives of those supporting higher-density living and mixed-use arrangements, claiming that these forms of developments are largely unsustainable with overcrowding, waste management problems and environmental degradation serving as potential downsides. One resident who has lived in cities with high-density and low-density designs vehemently opposed any moves to high-density mixed-use developments:

High-density development decreases our standard of living because we have a lack of space. I have lived in high and medium density for many years and I can't stand being in close proximity to other people. It is unnatural. Give me the suburbs with a quarter acre block anytime. I said there are alternatives that are better for our environment, and the number one is not releasing anymore land and not allowing the destruction of existing homes and buildings ('James Baker' online posting I3.3I h, I5 October 2010).

This diversity of views on future land use and management suggests that there should be some equitable middle ground for those who wish to live and work in high-medium-density or low-density areas. However, while the government recognizes the very high per capita land-use rates in the city (i.e. up to 20 times larger than exemplar sustainable developments) (ACT Government, 20IOb), some land-use experts argue that high-medium-density and low-density properties should be made equitably available in the community (PCA, 20II). Hence, in the foreseeable term the 
equitable use of city land for sustainable developments will remain a controversial and highly charged community issue (Beatley, I995; McDonald, I996; Towell, 20II).

Participant exchanges on energy reduction generated some heated discussion on the merits and drawbacks of using various energy sources including nuclear, coal, solar, wind and hydro-electric power ( 25 statements). Fifteen statements argued strongly for the exploration of green energy alternatives for servicing the city's future needs (e.g. residential solar photovoltaic systems), rather than using 'dirty' and ecologically unsound energy sources; whereas the remaining statements suggested that a more open dialogue be held on the use of less expensive non-green and alternative power sources. In addition, participant discussion was also directed at instituting city-wide energy-efficiency measures including greater energy saving compliance and regulations, energy recovery techniques for commercial operations, and higher standards for product energy efficiency (2I statements). Overall, the majority of statements were focused on using sustainable energy sources, coupled with energy savings.

The issue of water management attracted very few comments from the community. The major direction from the small number of community exchanges argued that future water management schemes in the city should be based around strong conservation measures and restrictions, high levels of recycled water use for public area maintenance, use of drought-tolerant groundcover, and the continued delivery of high-quality drinking water in the capital.

\section{SDP Issues - Economic Dimension}

In relation to the economic funding of future sustainable development in the city, participants strongly opined that the federal government should invest in Canberra and the ACT region (25 statements). This planning direction also came with a caveat that expenditure be equitably split with the federal government funding national projects and priorities, and the ACT government funding local and territory developments. Only seven statements suggested that the territory government should be the sole funding agency for all of the city's sustainable development. It should be noted that the economic dimension elicited very few online statements.

\section{SDP - The Online Process}

An analysis of the online posting profile showed some interesting trends in the use of this participation medium. First, the online exchanges generated 67,883 words over the 690 statements (average online statement length of approximately 99 words), with the shortest response being a simple two word 'I agree' and the longest statement covering 630 words. As a general observation, the online medium allowed participants to freely express opinions and views, no matter how radical or unusual. In an obvious example, the argumentative exchanges regarding the use of nuclear and coal-fired energy sources may have been quickly shutdown in other more environmentally or politically sensitive public forums.

Second, a review of computer server logs showed that the majority of online statements were written and shared after midday ( $12.00 \mathrm{~h}$ ) with over $75 \%$ of exchanges (519 postings) occurring in the afternoon and evening during the 3 -month consultation period. This suggested to us that, although most participants exercised opportunities to exchange views during working hours, they also used discretionary and post-work periods to consider sustainability issues and post statements.

Third, most of the online postings $(88 \%)$ did not provide real names or identifying information. Many participants elected to use pseudonyms (UseYourImagination, Michael IV, Jet and Pivotal) to suppress their real identities, thereby allowing them to freely and openly express their views in the online channel (note, personal information was subject to strict privacy provisions under the forum). Collectively, the online participation process allowed for an energetic exchange of viewpoints and interactive discussion on a wide range of sustainability-related issues that was free from the encumbrances of any potential censorship or political interference (e.g. free to express opinions, agree or disagree).

In summary, the online forum provided stakeholders with a voice in relation to SDP. Such participative democracy is open to anyone with Internet access and overcomes the common personal, political and temporal barriers. Given its convenience and mass communication potential, we support other studies that show that these emerging technological capabilities represent an important stage in the development of social media for public participation in policy making and planning (Howard and Gaborit, 2007; Brabham, 2009). 


\section{Sustainable Development Planning and Public Participation}

\section{Limitations of the Study}

We acknowledge that the study is limited in scope given that I96 registered participants is just a small segment of the total ACT population. In this respect, we have drawn on ACT government SDP benchmarking studies and expert opinions to further compare, refine and triangulate the participant group findings. We also note that very few statements related to the economic dimension of SDP were posted online. Accordingly, this limited our analysis of the economic dimension in the study.

\section{Conclusion}

In conclusion, the online public participation process raised several important and contentious SDP issues including efficient transport networks, land-use management and strategies, equitable living and working choices, and population changes. However, what the analysis shows is that while some issues can achieve strong stakeholder consensus (i.e. integrated transport networks, improved energy efficiency, water conservation measures), other issues may engender significant community disagreement, debate and argument (i.e. high-medium-density versus low-density mixed-use developments, population growth). This suggests that governments and stakeholders may need to adopt a highly balanced and even-handed approach to planning governance, particularly when setting city development goals, and creating policies, plans and strategies to achieve future sustainable developments (Newman, I993; Naess, I995; Cuthill 2002, 2010; John, 2009; Portney and Berry, 20I0; Berner et al., 20II). In support of this approach, contemporary studies show that cities can benefit from the integrated and fair consideration of future sustainable development policies, plans and frameworks (Rotmans and Van Asselt, 2000; Alker and McDonald, 2003; Steemers, 2003; Chiesura, 2004; Jim, 2004; Jenks and Dempsey, 2005; Bithas and Christofakis, 2006; Jabareen, 2006; Kenworthy, 2006; Webler and Tuler, 2006).

In relation to the online forums used to enable the public participation process, the results show that these types of dynamic mechanisms can accurately expose the important SDP issues. The NVIVo analysis of the online postings confirmed the areas of participant consensus while clearly exposing the more contentious issues and opposing participant views. In a practical sense, and although part of a much larger public participation process (Slotterback, 20II), the results of the online forum analysis provide an endorsement of this communication channel and posit a strong future role for information technologies in SDP participation and consultation (Conroy and Evans-Cowley, 2006; Howard and Gaborit, 2007). As a final point, we believe that this study supports an emergent area of research, namely Green Information Technology and Systems (Melville, 20I0). The relative scarcity of investigations that look into the capacity of Green Information Technology and Systems to share information and misinformation, and shape human beliefs, behaviours and reactions (Morgan and Dowlatabadi, I996; Pereira and O'Connor, I999), suggests further important directions for research that combine the power of information technology with sustainable development, environmental management and climate change.

\section{Acknowledgements}

The research infrastructure and software systems used in this study were developed and implemented under the ANU Research Grant CG-45-CIGSo7. The authors also wish to thank ACT government for making available the Canberra 2030 data and associated SDP reports and plans; and the Institution of Engineers Australia's 'Society for Sustainability and Environmental Engineering' who sponsored a technical forum to discuss the results of the study in July 20II. We also thank the article reviewers for their candid and helpful comments on the paper and research methods.

\section{References}

Agyeman J, Evans T. 2003. Toward Just Sustainability in Urban Communities: Building Equity Rights with Sustainable Solutions. The Annals of the American Academy of Political and Social Science 590: 35-53. 


\section{N. J. Martin et al.}

Alker S, McDonald A. 2003. Incorporating sustainable development into redevelopment. Sustainable Development II: I7I-I82.

Australian Capital Territory Government. 2004a. Canberra Plan - Towards Our Second Century. Publishing Services for the ACT Chief Minister's Department.

Australian Capital Territory Government. 2004b. Canberra City Spatial Plan. ACT Planning and Land Authority.

Australian Capital Territory Government. 2004c. The Sustainable Transport Plan for the ACT. ACT Planning and Land Authority.

Australian Capital Territory Government. 2007. Weathering the Change - The ACT Climate Change Strategy 2007-2025. Publishing Services for Sustainability Policy and Programs, Department of Territory and Municipal Services.

Australian Capital Territory Government. 2008. Canberra Plan - Towards Our Second Century. Publishing Services for the ACT Chief Minister's Department.

Australian Capital Territory Government. 20I0a. Canberra 2030 - A Time to Talk. http://www.canberra2030.org.au/ [Io February 20II].

Australian Capital Territory Government. 2oIob. Urban Form Analysis - Canberra Sustainability Performance (Technical Report). http://www. actpla.act.gov.au/_data/assets/pdf_file/0005/I9I93/Urban_form_analysis_-_technical_report.pdf [I February 20II].

Australian Capital Territory Government. 20II. Draft ACT Planning Strategy. http://www.actpla.act.gov.au/tools_resources/legislation_plans_registers/plans/planning_strategy [I December 20II].

Baber WF, Bartlett RV. 2005. Deliberative Green Politics: Democracy and Ecological Rationality. MIT Press: Cambridge MA.

Bagheri A, Hjorth, P. 2007. Planning for Sustainable Development: a Paradigm Shift Towards a Process-Based Approach. Sustainable Development I5: $83-96$.

Barbier EB. I987. The Concept of Sustainable Economic Development. Environmental Conservation I4(2): IOI-IIO.

Beatley T i995. Planning and Sustainability: The Elements of a New (Improved?) Paradigm. Journal of Planning Literature 9: 383-395.

Berner MM, Amos JM, Morse RS. 20II. What constitutes effective citizen participation in local government? Views from city stakeholders. Public Administration Quarterly 35:128-I63.

Bithas KP, Christofakis M. 2006. Environmentally Sustainable Cities. Critical Review and Operational Conditions. Sustainable Development I4: I77-I89.

Blassingame L. I998. Sustainable Cities: Oxymoron, Utopia or Inevitability. The Social Science Journal 35(I): I-I3.

Boshoff GBE. I996. Beating the participation trap. Ensuring sustainable community development in marginalized communities: a South African perspective. Sustainable Development 4: 7I-76.

Brabham DC. 2009. Crowdsourcing - The Public Participation Process for Planning Projects. Planning Theory 8(3): $242-262$.

Brueck TM. 2005. Strategic planning in today's dynamic world. Water Science and Technology: Water Supply 5(2): 53-62.

Caldwell LK. I984. Political Aspects of Ecologically Sustainable Development. Environmental Conservation II(4): $299-308$.

Chiesura A. 2004. The role of urban parks for the sustainable city. Landscape and Urban Planning 68: I29-138.

Commonwealth of Australia. 20Ir. Sustainable Australia: Sustainable Communities. A Sustainable Population Strategy for Australia. http://www. environment.gov.au/sustainability/population/publications/pubs/population-strategy.pdf [22 June 20II].

Conroy MM, Berke PR. 2004. What makes a good sustainable development plan? An analysis of factors that influence principles of sustainable development. Environment and Planning A 36: 138I-I396.

Conroy MM, Evans-Cowley J. 2006. E-participation in planning: an analysis of cities adopting on-line citizen participation tools. Environment and Planning C: Government and Policy 24: 37I-384.

Corley KG, Gioia, DA. 2004. Identity Ambiguity and Change in the Wake of a Corporate Spin-Off. Administrative Science Quarterly 49(2): I73-208.

Craig WJ. I998. The internet aids community participation in the planning process. Computers, Environment and Urban Systems 22(4): $393-404$.

Cuthill M. 2002. Exploratory research: citizen participation, local government and sustainable development in Australia. Sustainable Development Iо: $79-89$.

Cuthill M. 20I0. Strengthening the 'social' in sustainable development: developing a conceptual framework for social sustainability in a rapid urban growth region of Australia. Sustainable Development 18: 362-373.

Davidson F. I996. Planning for Performance: Requirements for Sustainable Development. Habitat International $20(3): 445-462$.

Denzin NK, Lincoln YS. 2005. The Handbook of Qualitative Research 3rd Edition. Sage Publications: Thousand Oaks, CA.

Donaldson T, Preston LE. I995. The Stakeholder Theory of the Corporation: Concepts, Evidence and Implications. Academy of Management Review 20: 65-91.

Elton Consulting. 20I0. Canberra 2030 - A Time to Talk: Outcomes Report. Elton: Canberra.

Freeman RE. I984. Strategic Management: A Stakeholder Approach. Pitman: Boston, MA.

Freeman RE, Wicks AC, Parmar B. 2004. Stakeholder theory and "the corporate objective revisited". Organization Science I5: 364-369.

Giddings B, Hopwood B, O’Brien G. 2002. Environment, Economy and Society: Fitting them together into Sustainable Development. Sustainable Development го: 187-196.

Girardet H. I999. Creating Sustainable Cities. Dartington: Green.

Haughton G, Hunter C. 2003. Sustainable Cities, Regional Policy and Development. Jessica Kingsley: London, UK.

Healey P, Shaw T. I997. Planners, plans and sustainable development. Regional Studies 27: 769-776.

Hellström D, Jeppsson U, Kärrman E. 2000. A framework for systems analysis of sustainable urban water management. Environmental Impact Assessment Review 20: 3II-32I.

Hjorth P, Bagheri A. 2006. Navigating towards sustainable development: a system dynamics approach. Futures 38: 74-92.

Holland L. I999. Horse-power: urban domestic recycling and the development of sustainable local community structures. Sustainable Development 7: 47-53. 


\section{Sustainable Development Planning and Public Participation}

Howard TLJ, Gaborit N. 2007. Using virtual environment technology to improve public participation in urban planning process. Journal of Urban Planning and Development 133: 233-24I.

Jabareen YR. 2006. Sustainable Urban Forms: Their Typologies, Models, and Concepts. Journal of Planning Education and Research 26: $38-52$. Jenks M, Dempsey N. 2005. Future Forma and Design for Sustainable Cities. Architectural Press: Oxford, UK.

Jim CY. 2004. Green-space preservation and allocation for sustainable greening of compact cities. Cities 2I(4): 3II-320.

John P. 2009. Can citizen governance redress the representative bias of political participation? Public Administration Review 69: 494-503.

Karlsson R 2005. Why the far-future matters to democracy today. Futures 37: 1095-II03.

Katz JE, Rice RE. 2002. Social Consequences of Internet Use: Access, Involvement and Interaction. MIT Press: Boston, MA.

Kenworthy JR. 2006. The eco-city: ten key transport and planning dimensions for sustainable city development. Environment and Urbanization I8: $67-85$.

Koontz T. 2006. Collaboration for sustainability? A framework for analyzing government impacts in collaborative-environmental management. Sustainability: Science, Practice, and Policy $\mathbf{1}$ : $15-24$.

Luke TW. 2005. Neither Sustainable nor Development: Reconsidering Sustainability in Development. Sustainable Development I3: 228-238.

McDonald GT. 1996. Planning as Sustainable Development. Journal of Planning Education and Research 15: 225-236.

Macnaghten P, Jacobs M. I997. Public identification with sustainable development: investigating cultural barriers to participation. Global Environmental Change 17: 5-24.

Melville NP. 20IO. Information systems innovation for environmental sustainability. MIS Quarterly 43(I): I-2I.

Miles MB, Huberman AM. 1997. Qualitative Data Analysis - An Expanded Case Book. 2nd ed. Sage Publications: Thousand Oaks, CA.

Moffatt I. I996. Sustainable Development: Principles, Analysis and Policies. Parthenon Publishing: London, UK.

Morgan MG, Dowlatabadi H. I996. Learning from Integrated Assessment of Climate Change. Climate Change 34(3/4): 337-368.

Naess P. 1995. Central dimensions in sustainable urban development. Sustainable Development 3(3): I20-I29.

Newman PWG. I993. Sustainable development and urban planning: principles and applications in an Australian context. Sustainable Development I(I): $25-40$.

Pereira AG, O'Connor M. I999. Information and Communication Technology and the Popular Appropriation of Sustainability Problems. International Journal of Sustainable Development 2(3): 4II-424.

Portney KE, Berry JM. 20IO. Participation and the pursuit of sustainability in U.S. cities. Urban Affairs Review 46: II9-I39.

Property Council of Australia (PCA). 20II. ACT Population Symposium finds Agreement on Big Issues. http://www.propertyoz.com.au/Blog/ archive/20II/O2/2I/I28.aspx [2I February 20II]

Reed M 2008. Stakeholder participation for environmental management: a literature review. Biological Conservation I4I: 24I7-243I.

Roseland M. I997. Dimensions of the Eco-City. Cities I4(4): 197-202.

Roseland M. 2000. Sustainable community development: integrating environmental, economic, and social objectives. Progress in Planning 54: 73-I32.

Roseland M. 2005. Towards Sustainable Communities: Resources for Citizens and their Governments. New Society Publishers: Gabriola, BC, Canada.

Rotmans J, Van Asselt MAB. 2000. Towards an Integrated Approach for Sustainable City Planning. Journal of Multi-Criteria Decision Analysis 9: IIO-I24.

Satterthwaite D. I997. Sustainable Cities or Cities that Contribute to Sustainable Development? Urban Studies 34(I0): I667-I69I.

Scott A I997. The role of forums in sustainable development: a case study of Cardigan Bay forum. Sustainable Development 5: I3I-I37.

Shutkin W. 2000. The Land That Could Be: Environmentalism and Democracy in the Twenty-First Century. MIT Press: Cambridge, MA.

Slotterback CS. 20II. Planners' perspectives on using technology in participatory processes. Environment and Planning B 38: 468-485.

Steemers K. 2003. Energy and the city: density, buildings and transport. Energy and Buildings 35: 3-I4.

The World Bank. 2010. Cities and Climate Change: An Urgent Agenda. The World Bank: Washington DC.

Thinh NX, Arlt G, Heber B, Hennersdorf J, Lehmann I. 2002. Evaluation of urban land-use structures with a view to sustainable development. Environmental Impact Assessment Review 22: 475-492.

Thrupp LA, Cabarle B, Zazueta A. I994. Participatory Methods in Planning \& Political Processes: Linking the Grassroots \& Policies for Sustainable Development. Agriculture and Human Values (Spring/Summer) II: 77-84.

Towell N. 20II. Plan for High Density Capital. The Canberra Times. http://www.canberratimes.com.au/news/local/news/general/plan-for-highdensity-capital/2327030.aspx [I8 October 20II].

United Nations. 20I0. United Nations Climate Change Conference, Cancun, Mexico, 29 November - Io December 20Io. Outcome of the work of the Ad Hoc Working Group on long-term Cooperative Action under the Convention http://unfccc.int/documentation/documents/advanced_search/items/3594.php?such=j\&meeting=\%22(AWGLCA), +thirteenth + session\%22\&sorted = agenda\#beg. [Iо February 2010 ]

Walsh M 2003. Teaching qualitative analysis using QSR NVivo. The Qualitative Report 8(2): 25I-256.

Wang X. 200I. Assessing public participation in U.S. cities. Public Performance Q Management Review 24: 322-336.

Webler T, Tuler S, Krueger R. 200I. What is a good public participation process? Environmental Management 27: $435-450$.

Webler T, Tuler S. 2006. Four perspectives on public participation process in environmental assessment and decision making. Policy Studies Journal 34: 699-722.

Winston N. 20I0. Regeneration of sustainable communities? Barriers to implementing sustainable housing in urban areas. Sustainable Development I8: 319-330. 